\title{
Real-World Effectiveness and Safety of Fingolimod in Patients with Multiple Sclerosis in the Czech Republic: Results from Core and Extension Parts of the GOLEMS Study up to 48 Months
}

Veronika Tichá ( $\square$ Veronika.Ticha@vfn.cz)

MS Center, Department of Neurology and Center of Clinical Neuroscience, First Faculty of Medicine and General University Hospital in Prague, Charles University, Prague

Zuzana Počíková

Novartis s.r.o., Prague

Josef Vytlačil

Novartis s.r.o., Prague

Radka Štěpánová

ANOVA CRO s.r.o., Zelená 2002/21a, 16000 Prague 6 - Dejvice

\section{Research Article}

Keywords: Fingolimod, Multiple sclerosis, GOLEMS extension study, Relapse, EDSS score

Posted Date: November 3rd, 2021

DOI: https://doi.org/10.21203/rs.3.rs-1007907/v1

License: (c) (i) This work is licensed under a Creative Commons Attribution 4.0 International License.

Read Full License

Version of Record: A version of this preprint was published at BMC Neurology on April 15th, 2022. See the published version at https://doi.org/10.1186/s12883-022-02656-8. 


\title{
Real-World Effectiveness and Safety of Fingolimod in Patients with Multiple Sclerosis in the Czech Republic: Results from Core and Extension Parts of the GOLEMS Study up to 48 Months
}

\author{
Veronika Ticháa, Zuzana Počíkováb, Josef Vytlačil ${ }^{b}$, Radka Štěpánovác
}

${ }^{a}$ MS Center, Department of Neurology and Center of Clinical Neuroscience, First Faculty of Medicine and General University Hospital in Prague, Charles University, Prague, Czech

Republic; ' Novartis s.r.o., Prague, Czech Republic; 'ANOVA CRO s.r.o., Zelená 2002/21a, 160 00 Prague 6 - Dejvice, Czech Republic

\section{Corresponding author:}

Dr. Veronika Tichá

Phone: +420737260268

\section{Email: Veronika.Ticha@vfn.cz}

Postal address: MS Center, Department of Neurology and Center of Clinical Neuroscience, First Faculty of Medicine, Charles University and General University Hospital in Prague, Katerinska 30, 12000 Praha 2, Czech Republic; [Veronika.Ticha@vfn.cz]

\section{Co-author details:}

Zuzana Počíková: Novartis s.r.o., Gemini, B building, Na Pankráci 1724/129, 14000 Prague 4, Czech Republic; [zuzana.pocikova@novartis.com]

Josef Vytlačil: Novartis s.r.o., Gemini, B building, Na Pankráci 1724/129, 14000 Prague 4, Czech Republic; [josef.vytlacil@novartis.com]

Radka Štěpánová: ANOVA CRO s.r.o., Zelená 2002/21a, 16000 Prague 6 - Dejvice, Czech Republic; [radka.stepanova@anova-cro.com]

Target journal: BMC Neurology

Word count: 2767

Figures and tables: 5 figures and 4 tables

References: 17 


\section{ABSTRACT (350/350 max words)}

\section{Background:}

Fingolimod, an oral sphingosine 1-phosphate receptor immunomodulator, is approved in Europe for multiple sclerosis (MS) patients with highly active disease despite a full and adequate course of treatment with $\geq 1$ disease-modifying therapy or patients with rapidly evolving severe relapsing-remitting MS. GOLEMS, a 12-month, national, multicenter, non-interventional, singlearm, real-world study showed a favorable benefit-risk profile of fingolimod in patients with MS in the Czech Republic. Here, we evaluated the long-term effectiveness and safety of fingolimod and its impact on disability progression and work capability for up to 48 months in patients with MS.

\section{Methods:}

The endpoints assessed were the incidence and severity of MS relapses in fingolimod-treated patients and the proportion of relapse-free patients up to 48 months of fingolimod treatment, change from baseline in the Expanded Disability Status Scale (EDSS) score, and change from baseline in work capability assessment. Efficacy outcomes were analyzed in the completed and efficacy sets, and safety was evaluated in all the enrolled patients.

\section{Results:}

Of 240 enrolled patients, 237 were included into efficacy set. Patients with a minimum of a 12month observation period in the core study who continued fingolimod treatment, were eligible to participate in the extension phase. Of 211 patients enrolled in extension study, 155 were evaluated in the completed set. Based on analysis of 48-month period of fingolimod treatment, 95/237 patients (40.1\%) in the efficacy set, 54/155 (34.8\%) in the completed set were free of relapses. The majority of relapses reported were moderate in intensity. Mean EDSS score remained stable throughout 48-month study period (Baseline, 3.4; Month 48, 3.6). No significant 
trend was observed in changes in work capability assessment or number of missed days of work. Of 240 enrolled patients, 147 (61.3\%) had $\geq 1$ treatment-emergent adverse event ( $A E)$ and 20 (8.3\%) reported serious AEs. In total, 45 patients (18.8\%) permanently discontinued treatment because of AEs related to study drug; two patients reported pregnancy after treatment initiation and subsequently discontinued the treatment; no deaths were reported.

\section{Conclusion:}

GOLEMS study demonstrated the sustained effectiveness and manageable safety profile of fingolimod under real-world conditions over 48 months in patients with MS.

Trial registration: Not applicable

\section{Keywords:}

Fingolimod; Multiple sclerosis; GOLEMS extension study; Relapse; EDSS score 


\section{BACKGROUND}

Multiple sclerosis (MS) is a chronic, autoimmune, inflammatory, demyelinating disease of the central nervous system (CNS) (Chun and Hartung, 2010; Compston and Coles, 2002) affecting approximately 2.3 million individuals worldwide (NationalMSSociety, 2019). Patients with MS require long-term treatment with disease-modifying therapies that can reduce the number of relapses and delay the progression of disability (Merkel et al., 2017) (Derwenskus, 2011).

Fingolimod (FTY720, Gilenya ${ }^{\circledR}$; Novartis Pharma AG) is a first-in-class, oral sphingosine 1phosphate receptor immunomodulator that acts as a functional antagonist by internalizing activated receptors (Chun and Hartung, 2010). S1P down-regulation prevents lymphocyte egress from lymphoid tissues, thereby reducing autoaggressive lymphocyte infiltration into the CNS. In Europe, fingolimod is approved for MS patients with highly active disease despite a full and adequate course of treatment with at least one disease-modifying therapy or patients with rapidly evolving severe relapsing-remitting MS (RRMS) (Gilenya_SmPC, 2019). As of 31 May, 2020 , it is estimated that $>303,600$ patients have been treated with fingolimod, corresponding to $>808,900$ patient-years of exposure in clinical trials and the post-marketing setting (Novartis Data on file).

The three large Phase 3 clinical trials of fingolimod-FREEDOMS (Kappos et al., 2010), FREEDOMS II (Calabresi et al., 2014), and TRANSFORMS (Cohen et al., 2010)—showed a significant reduction in relapse rate, magnetic resonance imaging-related lesion counts, disability progression, and brain volume loss versus placebo and intramuscular interferon $\beta-1 \mathrm{a}$ in patients with RRMS. These effects were sustained in the respective extension studies (Kappos et al., 2015) (Cohen et al., 2016), which demonstrated decreased MS disease activity and disability progression. In addition, the long-term observational study (LONGTERMS) also confirmed the safety and efficacy associated with the fingolimod treatment for up to 14 years in patients with relapsing MS (Cohen et al., 2019). Real-world evidence studies complement the 
randomized controlled trials by contributing to the understanding of long-term effectiveness and tolerability of therapies to uncover the best treatment paths in routine clinical practice (Ziemssen et al., 2016b).

The Gilenya (FingOLimod) in prescribing conditions defined by the CzEch regulator of drug reiMburSement (GOLEMS) study was planned to provide the requested healthcare outcomes data from MS patients receiving fingolimod under real-life conditions to the Health Authority and General Health Insurance Company of the Czech Republic (Ticha et al., 2017). The results from the 12-month GOLEMS study showed a favorable benefit-risk profile of fingolimod consistent with the pivotal Phase 3 trials (Ticha et al., 2017).

Here, we report the results from the core and extension parts of GOLEMS study, which evaluated the long-term effectiveness and safety of fingolimod treatment for up to 48 months in patients with MS.

\section{MATERIALS AND METHODS}

\subsection{Study design}

GOLEMS was a national, multicenter, observational, non-interventional, single-arm study in the Czech Republic, conducted between November 2012 and March 2018. (Ticha et al., 2017). All existing MS centers in the Czech Republic were asked to participate in this study. As this was a non-interventional study, there were no special protocol-mandated visits or procedures associated with the study. Overall, in the core and extension, patients in the study were observed for a period of 4 years. Data recorded during observations at the second, third, and fourth year of the study were used for the evaluation of long-term therapy outcomes. All patients were assessed and monitored as per the revised label issued on March 20, 2012. Fingolimod prescription was at the discretion of both the treating physician and the patient and was independent of participation in the study. 


\subsection{Patient population}

Patients with a minimum of a 12-month observation period in the core study (Ticha et al., 2017), who continued treatment with fingolimod, and had signed an informed consent form were eligible to participate in the extension phase. In total, 240 patients were enrolled in the core GOLEMS study and 211 patients entered the extension study.

The study was conducted in compliance with the ethical principles of the Declaration of Helsinki and the International Conference on Harmonization Good Clinical Practice Guidelines (Declaration_of_Helsinki, 2013). The protocol was approved by an independent ethics committee or institutional review board for each study site, and all patients provided written informed consent before commencing trial-related procedures.

\subsection{Study endpoints}

The endpoints assessed were incidence and severity of MS relapses during the whole 48-month treatment period; change from baseline in Expanded Disability Status Scale (EDSS) score at each post-baseline visit; and changes in work capability assessment (Work Productivity and Activity Impairment Questionnaire-General Health [WPAI-GH] scores and number of missed days of work) from baseline to the 48 months.

The proportion of relapse-free patients and time to first relapse were also analyzed for subgroups of patients with EDSS scores of $\leq 3$ and $>3$ at baseline. In addition, the proportion of relapse-free patients in a subgroup of patients treated with natalizumab before fingolimod initiation was also assessed.

Safety was assessed by adverse events (AEs), serious AEs (SAEs), performance of first-dose observation, ophthalmic examinations, and laboratory assessments (liver function tests and lymphocyte counts). 
Medical health record data were collected by the investigators using the web-based software OpenClinica $^{\circledR}$, an electronic data capture system compliant with the guidelines of Good Clinical Practice (21 CFR Part 11) (Ticha et al., 2017).

\subsection{Statistical analyses}

As the study was non-interventional and objectives were exploratory, no formal hypothesis was set for this study. For categorical data, counts and percentages were reported; for efficacy variables, $95 \%$ confidence intervals (Cls) for percentages were calculated. For continuous data, descriptive statistics including number of available observations, mean, standard deviation, median, lower and upper quartiles, minimum and maximum were reported; for efficacy variables, $95 \%$ Cls for the mean or median were calculated.

In this study, the outcomes were assessed in two different sets of patient populations. The efficacy set $(\mathrm{N}=237)$ comprised all treated patients except for three who discontinued the study treatment at Month 3. The reason for discontinuation was neither due to efficacy nor safety issues. The completed set $(\mathrm{N}=155)$ included all patients who completed the 48 -month treatment period (even if the patient temporarily discontinued the study).

Efficacy data were evaluated in the efficacy and completed sets. The primary analysis was performed using the completed set. The safety analysis was performed in the safety set, consisting of all enrolled patients.

\section{RESULTS}

\subsection{Patient disposition and demographics}

A total of 240 patients were enrolled in the study. Out of 240 patients at the study start, 211 patients entered the extension and 155 completed the 48-month period). Overall in the GOLEMS core study, $70.4 \%$ of patients (169/240) were women, the average age was 37 years at baseline, and the mean occurrence of the first symptoms of MS was 10.35 years before the 
study entry. During the year prior to fingolimod treatment initiation, $19.6 \%$ of patients had no relapse, $22.5 \%$ had one relapse, $57.9 \%$ had two or more relapses. The maximum number of relapses in one patient within the year prior to fingolimod treatment was four. During the 2 years prior to fingolimod treatment, $45 \%$ of patients had $>2$ relapses. Mean EDSS score at baseline was 3.4 and the mean number of missed days of work during the 3 months prior to study entry was 7.9 days $(n=24)$. (Table 1$)$.

\subsection{Incidence and severity of MS relapses in patients treated with fingolimod for 48 months}

Overall, $40.1 \%$ in the efficacy set and $34.8 \%$ in the completed set were free of relapses (Figure 1A). In patients who experienced relapses, the majority of relapses reported were moderate in intensity (efficacy set [52.8\%] and completed set [53.5\%] (Figure 1B).

Among patients with relapses, 43.7\% (62/142) in the efficacy set and $44.6 \%(45 / 101)$ in the completed set had one relapse during 48 months (Figure 2). The mean number of relapses per patient per year in the efficacy set was $0.55(95 \% \mathrm{Cl}: 0.45 ; 0.66)$ and in the completed set was 0.36 (95\% Cl: 0.30; 0.43).

The proportion of relapse-free patients was higher in the subgroup of patients with a baseline EDSS score $\leq 3$ versus those with an EDSS score $>3$ (Figure 3 ). In the efficacy set, $41.7 \%$ of patients with a baseline EDSS score $\leq 3$ were relapse-free versus $25.9 \%$ with a baseline EDSS

score $>3$. Similarly, in the completed set, $36.7 \%$ with a baseline EDSS score $\leq 3$ were relapsefree versus $28.9 \%$ with an EDSS score $>3$.

\subsection{Distribution of severity of relapses over time}

The proportion of relapse-free patients decreased evenly over time. In the efficacy set, $91.1 \%$ of patients were relapse free at Month 1 and $40.1 \%$ were relapse free at Month 48 . Similarly, in the 
completed set, $92.9 \%$ were free from relapses at Month 1 and $34.8 \%$ were relapse free at the Month 48 visit.

In the efficacy set, the number of relapses reported as mild decreased and the number of patients with a moderate relapse slightly increased; in the completed set, moderate relapses were more frequent than mild relapses from the beginning to the end of treatment. The number of severe relapses remained stable in both of these sets (Figure 4).

\subsection{Factors influencing the occurrence of an MS relapse}

In the efficacy set, age, EDSS score, and number of relapses during the 2 years prior to treatment significantly correlated with the occurrence of MS relapse in the first 48 months of fingolimod treatment (Table 2). With every 10-year increase in the age at baseline, the chance of being free of relapses was almost 1.5 times higher. For every 1-point increase in baseline EDSS score, the chance of being free of relapses was about $20 \%$ lower. If the number of relapses during the last 2 years was higher by one relapse, then the chance of being relapse free was about $30 \%$ lower. In the completed set, none of the variables in the model showed a significant effect on being relapse free.

\subsection{EDSS scores and work capability assessment}

EDSS scores were found to be stable over the observation period and no significant changes were observed during fingolimod treatment in both the efficacy and completed sets (Figure 5). Median EDSS score was around 3.5 at each visit and around 4.5 at the time of relapses.

Analysis of the WPAI-GH questionnaire, number of missed days of work, changes in work capability assessment, and changes in the number of missed days of work did not reveal any trends. 


\subsection{Relapse status in patients receiving natalizumab before fingolimod initiation}

At M48, among 59 patients who had received natalizumab one year before fingolimod treatment initiation, 19 (32.2\%) were relapse free after 48 months of treatment. Of 40 patients with relapses, 16 (40\%) had mild relapses, $18(45 \%)$ had moderate relapses, and $6(15 \%)$ had severe relapses.

\subsection{Safety results}

Overall, 147 (61.3\%) patients from safety set reported 222 AEs (Table 3). Among these, 100 AEs were related to the study drug in 76 patients (31.7\%), and $21 \mathrm{AEs}$ in 20 patients (8.3\%) were reported as SAEs (Table 4).

Overall, 45 patients (18.8\%) experienced AEs leading to permanent discontinuation of fingolimod treatment. There were no deaths observed in this study. The liver function tests were abnormal at baseline in $4.6 \%$ of patients and in $15.3-29.4 \%$ of patients during treatment. The mean lymphocyte count ranged from $0.571 \times 10^{9} / \mathrm{L}$ to $0.654 \times 10^{9} / \mathrm{L}$ during the 12 months of fingolimod treatment. The ophthalmologic examination was abnormal for one patient at the baseline, Month 9, and Month 12 visits but there are large proportions of missing data for this examination.

\section{DISCUSSION}

The GOLEMS study evaluated the long-term efficacy and safety outcomes of fingolimod treatment for up to 48 months in patients with MS. In this study, $40.1 \%$ of patients treated with fingolimod were free of relapses over a period of 48 months. The number of relapse-free patients decreased evenly over time. EDSS score did not change significantly over time and no significant impairment was recorded. Changes in work capability assessment analyzed by the WPAI-GH questionnaire and the number of missed days of work did not reveal any trends. Out 
of 240 patients, 147 had at least one treatment-emergent AE and only 20 (8.3\%) patients had SAEs. Age, EDSS score at baseline, and number of relapses during the 2 years prior to fingolimod treatment significantly correlated with the occurrence of MS relapse during the 48 months of fingolimod treatment.

Similar to GOLEMS, PANGAEA—a prospective, observational, 5-year registry study—was another real-world study that determined the incidence of safety-related parameters and monitored the general safety profile of fingolimod in routine practice in Germany. The GOLEMS study had similar results to the 36-month interim results of the PANGAEA study $(n=1518)$ (Ziemssen et al., 2019). At 36 months of PANGAEA study, more than $58.2 \%$ of patients were free from relapses. At 48 months of GOLEMS study, 40.1\% were relapse-free indicating that the percentage of relapse-free patients decrease over time.

After 48 months of fingolimod treatment in GOLEMS, the average number of relapses per patient per year was 0.36 in the completed analysis set compared with 0.29 in the interim analysis of PANGAEA ( $\mathrm{N}=4229$ ) (Ziemssen et al., 2016a). In the GOLEMS study, the mean number of relapses per patient per year in the 12 months before fingolimod initiation was 1.6, which was comparable to the 1.5 relapses in PANGAEA, with a relative reduction of $67 \%$ and $72 \%$, respectively.

During the 36-month PANGAEA study, EDSS scores remained stable and only a small proportion of patients $(<10 \%)$ experienced confirmed disability worsening during any 12-month follow-up period. In addition, improvements in EDSS scores were observed in an increasing proportion of patients in each 12-month follow-up period (Ziemssen et al., 2019). Similarly, patients in the GOLEMS trial treated with fingolimod did not show any significant changes in EDSS score during the treatment period. 
The types of AEs were similar in both studies and results did not show any new safety signals related to fingolimod treatment.

As there were no specific protocol-mandated visits in the study, evaluations were determined by treating physicians according to the local prescribing information. However, the noninterventional design of the study reflects real-life data.

One of the major limitations of this study was the large amount of missing data for the assessment of changes in work capability due to the low response rate ( $10 \%)$ in completing the WPAI-GH questionnaires, which prevented any meaningful statistical interpretation. Another limitation of the study include the number of discontinuations throughout the study; of 240 enrolled patients, 155 (65\%) completed the 48-month study period.

\section{CONCLUSION}

Long-term treatment with fingolimod showed favorable efficacy and safety by reducing the frequency and severity of MS relapses and by the low incidence of SAEs under real-world conditions in the Czech Republic.

\section{Abbreviations:}

$\mathrm{AE}$, adverse event; $\mathrm{Cl}$, confidence interval; CNS; central nervous system; EDSS, Expanded Disability Status Scale; KM, Kaplan-Meier; GOLEMS, Gilenya (FingOLimod) in prescribing conditions defined by the CzEch regulator of drug reiMburSement; S1P, sphingosine 1phosphate; SAE, serious adverse event; WPAI-GH, Work Productivity and Activity Impairment Questionnaire-General Health 


\section{DECLARATION}

\section{Ethics approval and consent to participate:}

The study was conducted in compliance with the ethical principles of the Declaration of Helsinki and the International Conference on Harmonization Good Clinical Practice Guidelines (Declaration_of_Helsinki, 2013). The protocol was approved by an independent ethics committee or institutional review board for each study site, and all patients provided written informed consent before commencing trial-related procedures. Ethics Committee in each of the participating hospitals include Ethics committee of St. Anne's University Hospital Brno, Pekařská 53, 656 91, Brno; Ethics committee of Pardubice Hospital, Kyjevská 44, 532 03, Pardubice; Ethics committee of General University Hospital in Prague, Karlovo náměstí 32, 128 08, Prague; Ethics committee of Thomayer's Hospital, Vídeňská 800, 140 59, Prague; Ethics committee of University Hospital in Moto, V Úvalu 84, 150 06, Prague; Ethics committee of Royal Vinohrady Teaching Hospital, Šrobárova 1150/50, Prague; Ethics committee of Hospital in Teplice, Duchcovská 962/53, 41501, Teplice; Ethics committee of University Hospital in Pilsen, Alej Svobody 80, 304 60, Pilsen; Ethics committee of University Hospital in Hradec Králové, Sokolská 581, 500 05, Hradec Králové; Ethics committee of Hospital in Jihlava, Vrchlického 59, 586 33, Jihlava; Ethics committee of University Hospital in Olomouc, I.P. Pavlova 185/6, 779 00, Olomouc; Ethics committee of University Hospital in Ostrava, 17. listopadu 1790, 708 52, Ostrava; Ethics committee of Bat’a Regional Hospital in Zlín, Havličkovo nábř. 600, 762 75, Zlín; Ethics committee of University Hospital Brno, Jihlavská 340/20, 625 00, Brno and Ethics committee of České Budějovice Hospital, B. Němcové 54, 370 01, České Budějovice.

\section{Consent for publication}

Not applicable. 


\section{Availability of data and materials}

The data that support the findings of this study are available from [Novartis s.r.o.] but restrictions apply to the availability of these data, which were used under license for the current study, and so are not publicly available. Data are however available from the authors upon reasonable request and with permission of [Novartis s.r.o.]. Any additional data/files may be obtained from the corresponding author (Dr. Veronika Tichá) on reasonable request.

\section{Competing interests}

Veronika Tichá has received financial support for conference travel, consultancy fees, and speaker honoraria from Biogen, Novartis, Merck Serono, Teva, Actelion, and Receptos. She is an employee of MS Center, Department of Neurology and Center of Clinical Neuroscience, Charles University in Prague, $1^{\text {st }}$ Faculty of Medicine and General University Hospital in Prague.

Zuzana Počíková and Josef Vytlačil are employees of Novartis s.r.o., Prague, Czech Republic. Radka Štěpánová is an employee of ANOVA CRO s.r.o., Zelená 2002/21a, 16000 Prague 6 Dejvice, Czech Republic.

\section{Funding}

This work was supported by Novartis s.r.o., Prague, Czech Republic. 


\section{Authors' contributions}

Veronika Tichá: Investigation, Methodology, Supervision, Writing - review \& editing

Zuzana Počíková: Writing - review \& editing,

Josef Vytlačil: Writing - Writing - review \& editing,

Radka Štěpánová: Data curation, Formal analysis, Visualization, Writing - review \& editing,

\section{Acknowledgements}

The authors would like to thank the patients and investigators who participated in the study. The authors take full responsibility for the content of the paper. The authors would also like to thank Saimithra Thammera and Sreelatha Komatireddy (both of Medical Communications, Novartis Healthcare Pvt. Ltd., Hyderabad, India) for writing assistance, editorial review assistance, and in coordinating author review. 


\section{References}

1. Declaration_of_Helsinki, 2013. Declaration of Helsinki: ethical principles for medical research involving human subjects. Fortaleza, Brazil: World Medical Association,, https://www.wma.net/policies -post/wma-declaration-of-helsinki-ethical-principles-for-medicalresearch-involving-human-subjects ed.

2. Calabresi, P.A., Radue, E.W., Goodin, D., Jeffery, D., Rammohan, K.W., Reder, A.T., Vollmer, T., Agius, M.A., Kappos, L., Stites, T., Li, B., Cappiello, L., von Rosenstiel, P., Lublin, F.D., 2014. Safety and efficacy of fingolimod in patients with relapsing-remitting multiple sclerosis (FREEDOMS II): a double-blind, randomised, placebo-controlled, phase 3 trial. The Lancet. Neurology 13(6), 545-556.

3. Chun, J., Hartung, H.P., 2010. Mechanism of action of oral fingolimod (FTY720) in multiple sclerosis. Clinical neuropharmacology 33(2), 91-101.

4. Cohen, J.A., Barkhof, F., Comi, G., Hartung, H.P., Khatri, B.O., Montalban, X., Pelletier, J., Capra, R., Gallo, P., Izquierdo, G., Tiel-Wilck, K., de Vera, A., Jin, J., Stites, T., Wu, S., Aradhye, S., Kappos, L., 2010. Oral fingolimod or intramuscular interferon for relapsing multiple sclerosis. The New England journal of medicine 362(5), 402-415.

5. Cohen, J.A., Khatri, B., Barkhof, F., Comi, G., Hartung, H.P., Montalban, X., Pelletier, J., Stites, T., Ritter, S., von Rosenstiel, P., Tomic, D., Kappos, L., 2016. Long-term (up to 4.5 years) treatment with fingolimod in multiple sclerosis: results from the extension of the randomised TRANSFORMS study. Journal of neurology, neurosurgery, and psychiatry 87(5), 468-475.

6. Cohen, J.A., Tenenbaum, N., Bhatt, A., Zhang, Y., Kappos, L., 2019. Extended treatment with fingolimod for relapsing multiple sclerosis: the 14 -year LONGTERMS study results. Therapeutic advances in neurological disorders 12, 1756286419878324.

7. Compston, A., Coles, A., 2002. Multiple sclerosis. Lancet (London, England) 359(9313), 1221 1231.

8. Derwenskus, J., 2011. Current disease-modifying treatment of multiple sclerosis. The Mount Sinai journal of medicine, New York 78(2), 161-175.

9. Gilenya_SmPC, 2019. GILENYA [Summary of Product Characteristics]. Novartis Pharma GmbH, Nuremberg, Germany, p. 72.

10. Kappos, L., O'Connor, P., Radue, E.W., Polman, C., Hohlfeld, R., Selmaj, K., Ritter, S., Schlosshauer, R., von Rosenstiel, P., Zhang-Auberson, L., Francis, G., 2015. Long-term effects of fingolimod in multiple sclerosis: the randomized FREEDOMS extension trial. Neurology 84(15), 1582-1591.

11. Kappos, L., Radue, E.W., O'Connor, P., Polman, C., Hohlfeld, R., Calabresi, P., Selmaj, K., Agoropoulou, C., Leyk, M., Zhang-Auberson, L., Burtin, P., 2010. A placebo-controlled trial of oral fingolimod in relapsing multiple sclerosis. The New England journal of medicine 362(5), 387-401.

12. Merkel, B., Butzkueven, H., Traboulsee, A.L., Havrdova, E., Kalincik, T., 2017. Timing of highefficacy therapy in relapsing-remitting multiple sclerosis: A systematic review. Autoimmunity reviews 16(6), 658-665.

13. NationalMSSociety, 2019. MS Prevalence FAQs. 2019).

14. Ticha, V., Kodym, R., Pocikova, Z., Kadlecova, P., 2017. Real-World Outcomes in FingolimodTreated Patients with Multiple Sclerosis in the Czech Republic: Results from the 12-Month GOLEMS Study. Clinical drug investigation 37(2), 175-186.

15. Ziemssen, T., Albrecht, H., Haas, J., Klotz, L., Lang, M., Lassek, C., Schmidt, S., Tackenberg, B., Cornelissen, C., 2016a. 4 years PANGAEA: effectiveness update of a 5 year non-interventional study on the daily use of fingolimod in Germany. Mult Scler J 22(3), 1-306.

16. Ziemssen, T., Hillert, J., Butzkueven, H., 2016b. The importance of collecting structured clinical information on multiple sclerosis. BMC medicine 14, 81.

17. Ziemssen, T., Lang, M., Tackenberg, B., Schmidt, S., Albrecht, H., Klotz, L., Haas, J., Lassek, C., Couto, C.A., Findlay, J.A., Cornelissen, C., 2019. Real-world persistence and benefit-risk profile of fingolimod over 36 months in Germany. Neurology $(\mathrm{R})$ neuroimmunology \& neuroinflammation 6(3), e548. 
Table 1. Patient demographics and baseline characteristics

\begin{tabular}{|c|c|}
\hline Parameter & $\mathrm{N}=\mathbf{2 4 0}$ \\
\hline \multicolumn{2}{|l|}{ Age, years } \\
\hline Mean $( \pm S D)$ & $37.4( \pm 9.27)$ \\
\hline Median $\left(Q_{1} ; Q_{3}\right)$ & $37.0(31.0 ; 43.0)$ \\
\hline Min; Max & $18 ; 67$ \\
\hline \multicolumn{2}{|l|}{ Sex, n (\%) } \\
\hline Male & $71(29.6)$ \\
\hline Female & $169(70.4)$ \\
\hline \multicolumn{2}{|c|}{ Time since first MS symptom prior to study entry, years } \\
\hline Mean ( \pm SD) & $10.35( \pm 6.70)$ \\
\hline Median $\left(Q_{1} ; Q_{3}\right)$ & $9.42(5.22 ; 14.26)$ \\
\hline Min; Max & $0.4 ; 38.5$ \\
\hline $\begin{array}{l}\text { Frequency of relapses d } \\
n(\%)[95 \% \mathrm{Cl}]\end{array}$ & \\
\hline
\end{tabular}




\begin{tabular}{|c|c|}
\hline Parameter & $\mathrm{N}=\mathbf{2 4 0}$ \\
\hline Patients with no relapse & $47(19.6)[14.8 ; 25.2]$ \\
\hline Patients with 1 relapse & $54(22.5)[17.4 ; 28.3]$ \\
\hline Patients with 2 relapses & 102 (42.5) [36.2; 49.0] \\
\hline Patients with $>2$ relapses & $37(15.4)[11.1 ; 20.6]$ \\
\hline Number of MS relapses within the year prior to fingolimod treatment & $\mathrm{N}=240$ \\
\hline Mean $( \pm S D)$ & $1.6( \pm 1.02)$ \\
\hline Median $\left(Q_{1} ; Q_{3}\right)$ & $2.0(1.0 ; 2.0)$ \\
\hline Min; Max & $0 ; 4$ \\
\hline \multicolumn{2}{|l|}{ Frequency of relapses in the 2 years prior to fingolimod treatment, $\mathrm{n}(\%)$} \\
\hline Patients with no relapse & 35 (14.6\%) [10.4; 19.7] \\
\hline Patients with 1 relapse & 27 (11.3) [7.6; 15.9] \\
\hline Patients with 2 relapses & $70(29.2)[23.5 ; 35.4]$ \\
\hline Patients with $>2$ relapses & $108(45.0)[38.6 ; 51.5]$ \\
\hline \multicolumn{2}{|l|}{ Number of MS relapses in the 2 years prior to fingolimod treatment } \\
\hline Mean ( \pm SD) & $2.3( \pm 1.46)$ \\
\hline
\end{tabular}




\begin{tabular}{|l|c|}
\hline Parameter & $\mathbf{N}=\mathbf{2 4 0}$ \\
\hline Median $\left(\mathrm{Q}_{1} ; \mathrm{Q}_{3}\right)$ & $2.0(1.0 ; 3.0)$ \\
\hline Min; Max & $0 ; 9$ \\
\hline EDSS score for the 3 months prior to study entry or at the start of fingolimod \\
treatment & $3.4( \pm 1.26)$ \\
Mean $( \pm S D)$ & $3.5(2.5 ; 4.5)$ \\
Median $\left(\mathrm{Q}_{1} ; \mathrm{Q}_{3}\right)$ & $0 ; 6$ \\
Min; Max & \\
\hline Number of missed days of work during the 3 months prior to study entry & $7.9( \pm 19.66)$ \\
Mean $( \pm S D)$ & $0.0(0.0 ; 6.0)$ \\
Median $\left(\mathrm{Q}_{1} ; \mathrm{Q}_{3}\right)$ & $0.0 ; 90.0$ \\
Min; Max & \\
\hline
\end{tabular}

Cl, confidence interval; EDSS, Expanded Disability Status Scale; Max, maximum; Min, minimum; N, number of patients; $Q_{1}$, lower quartile; $Q_{3}$, upper quartile; SD, standard deviation

Table 2. Factors influencing the occurrence of an MS relapse for the first 48 months of fingolimod treatment (efficacy set, $\mathrm{N}=237$ ) 


\begin{tabular}{|c|c|c|c|}
\hline Parameter & Unit & $p$-value & $\begin{array}{c}\text { Odds ratio (Wald 95\% Cl) } \\
\text { estimate for } \\
\text { being "relapse free" }\end{array}$ \\
\hline Age at baseline, years & 10.0 & 0.0372 & $1.467(1.023 ; 2.104)$ \\
\hline EDSS score at baseline & 1.0 & 0.0335 & $0.765(0.598 ; 0.979)$ \\
\hline $\begin{array}{l}\text { Number of relapses during the year before } \\
\text { the start of fingolimod treatment }\end{array}$ & 1.0 & 0.7551 & $1.088(0.641 ; 1.845)$ \\
\hline $\begin{array}{l}\text { Number of relapses during the } 2 \text { years } \\
\text { before the start of fingolimod treatment }\end{array}$ & 1.0 & 0.0452 & $0.680(0.467 ; 0.992)$ \\
\hline $\begin{array}{l}\text { Severity of the last relapse before the start } \\
\text { of fingolimod treatment }\end{array}$ & 1.0 & 0.4669 & $0.829(0.500 ; 1.374)$ \\
\hline Disease duration (days) & 1.0 & 0.1720 & $1.000(1.000 ; 1.000)$ \\
\hline \multicolumn{4}{|l|}{ Type of previous MS therapya } \\
\hline Group 2 vs Group 1 & 1.0 & 0.5451 & $0.787(0.337 ; 1.835)$ \\
\hline Group 3 vs Group 1 & 1.0 & 0.6987 & $1.015(0.506 ; 2.035)$ \\
\hline
\end{tabular}

Rows indicated in bold format show statistically significant data

Duration of the diagnosis was calculated as the difference between the date of starting fingolimod treatment and the date of diagnosis.

aPatients were categorized into three groups according to the type of the previous therapy of MS: Group 1 - patients treated with any interferon or glatiramer acetate; Group 2 - patients treated with 
natalizumab in a period of at least 3 months before initiating fingolimod treatment; Group 3 - patients treated with another medication in addition to the medications stated above

CI, confidence interval; EDSS, Expanded Disability Status Scale; MS, multiple sclerosis; N, number of patients

Table 3. Summary of AEs (Safety set) $(\mathrm{N}=240)$

\begin{tabular}{|c|c|c|}
\hline Parameter & AE count & n (\%) \\
\hline Any treatment-emergent $\mathrm{AE}$ & 222 & $147(61.3)$ \\
\hline \multicolumn{3}{|l|}{ Relationship to study drug } \\
\hline No & 122 & $89(37.1)$ \\
\hline Yes & 100 & $76(31.7)$ \\
\hline \multicolumn{3}{|l|}{ Outcome } \\
\hline Completely recovered & 140 & $94(39.2)$ \\
\hline Condition still present and unchanged & 46 & $42(17.5)$ \\
\hline Condition improving & 27 & $26(10.8)$ \\
\hline Recovered with sequelae & 6 & $6(2.5)$ \\
\hline Condition deteriorated & 2 & $2(0.8)$ \\
\hline $\begin{array}{l}\text { Completely recovered, condition still present and } \\
\text { unchanged }\end{array}$ & 1 & $1(0.4)$ \\
\hline
\end{tabular}

$\mathrm{AE}$, adverse event, $n$, number of patients; $N$, total number of patients 
Table 4. Summary of SAEs (Safety set) $(\mathrm{N}=240)$

\begin{tabular}{|c|c|c|}
\hline Parameter & SAE count & n (\%) \\
\hline Any treatment-emergent SAE & 21 & $20(8.3)$ \\
\hline \multicolumn{3}{|l|}{ Relationship to study drug } \\
\hline No & 12 & $11(4.6)$ \\
\hline Yes & 9 & $9(3.8)$ \\
\hline \multicolumn{3}{|l|}{ Outcome } \\
\hline Completely recovered & 10 & $9(3.8)$ \\
\hline Condition still present and unchanged & 3 & $3(1.3)$ \\
\hline Condition improving & 3 & $3(1.3)$ \\
\hline Recovered with sequelae & 4 & $4(1.7)$ \\
\hline $\begin{array}{l}\text { Completely recovered, condition still present and } \\
\text { unchanged }\end{array}$ & 1 & $1(0.4)$ \\
\hline \multicolumn{3}{|l|}{ SAEs } \\
\hline MS relapse & 4 & $4(1.7)$ \\
\hline Hepatopathy & 2 & $2(0.8)$ \\
\hline Epileptic seizure & 2 & $1(0.4)$ \\
\hline
\end{tabular}




\begin{tabular}{|c|c|c|}
\hline Parameter & SAE count & n (\%) \\
\hline Breast cancer & 1 & $1(0.4)$ \\
\hline Bronchopneumonia & 1 & $1(0.4)$ \\
\hline Cerebral infarction & 1 & $1(0.4)$ \\
\hline Cerebrovascular accident & 1 & $1(0.4)$ \\
\hline Disease progression & 1 & $1(0.4)$ \\
\hline Gynecological infection & 1 & $1(0.4)$ \\
\hline Herpes zoster & 1 & $1(0.4)$ \\
\hline Humerus fracture & 1 & $1(0.4)$ \\
\hline Insufficient treatment effect & 1 & $1(0.4)$ \\
\hline Joint and muscle pain & 1 & $1(0.4)$ \\
\hline Macular edema & 1 & $1(0.4)$ \\
\hline Rebound of MS & 1 & $1(0.4)$ \\
\hline Spastic bronchitis & 1 & $1(0.4)$ \\
\hline
\end{tabular}

SAE, serious adverse event, $n$, number of patients; $N$, total number of patients 
Figure 1. Proportion of patients with and without relapses (A) and severity of relapses during 48 months of treatment with fingolimod (B)

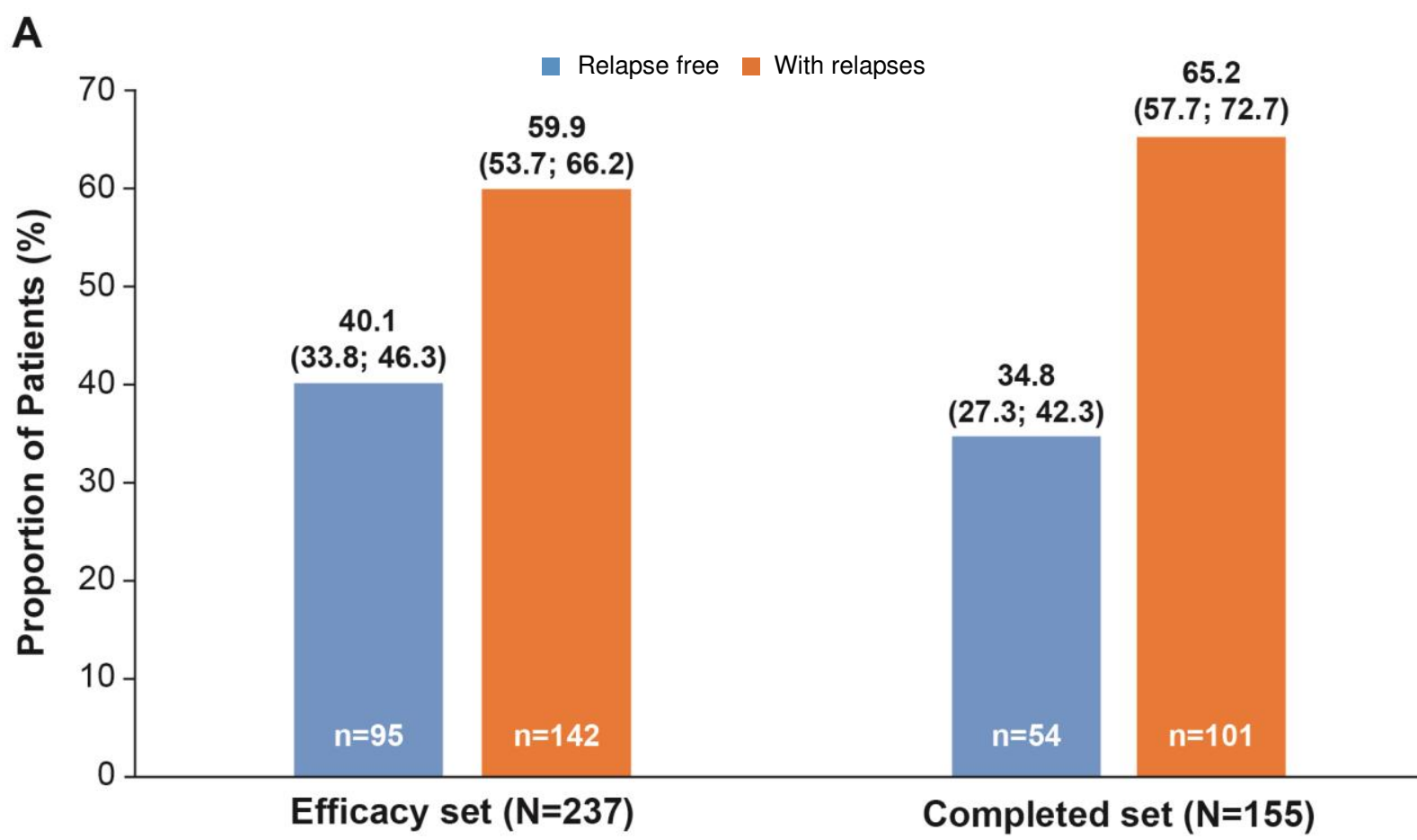

B

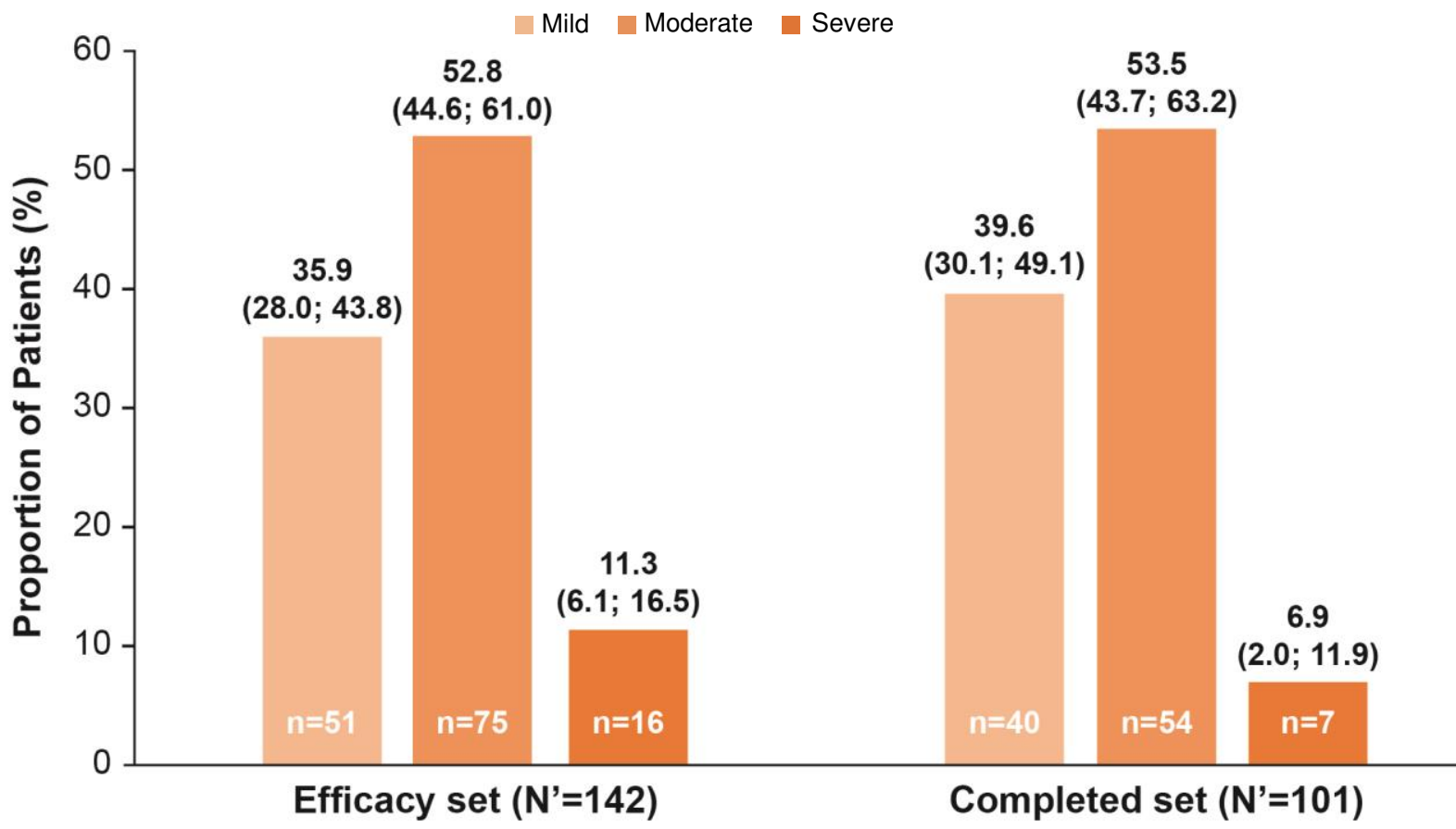


Data presented as percentage of patients (Wald 95\% Cl)

$\mathrm{Cl}$, confidence interval; MS, multiple sclerosis; N, total number of patients in the set; $\mathrm{N}$ ', total number of patients with relapses; $n$, number of patients with the outcome

Figure 2. Frequency of MS relapses 48 months of treatment with fingolimod

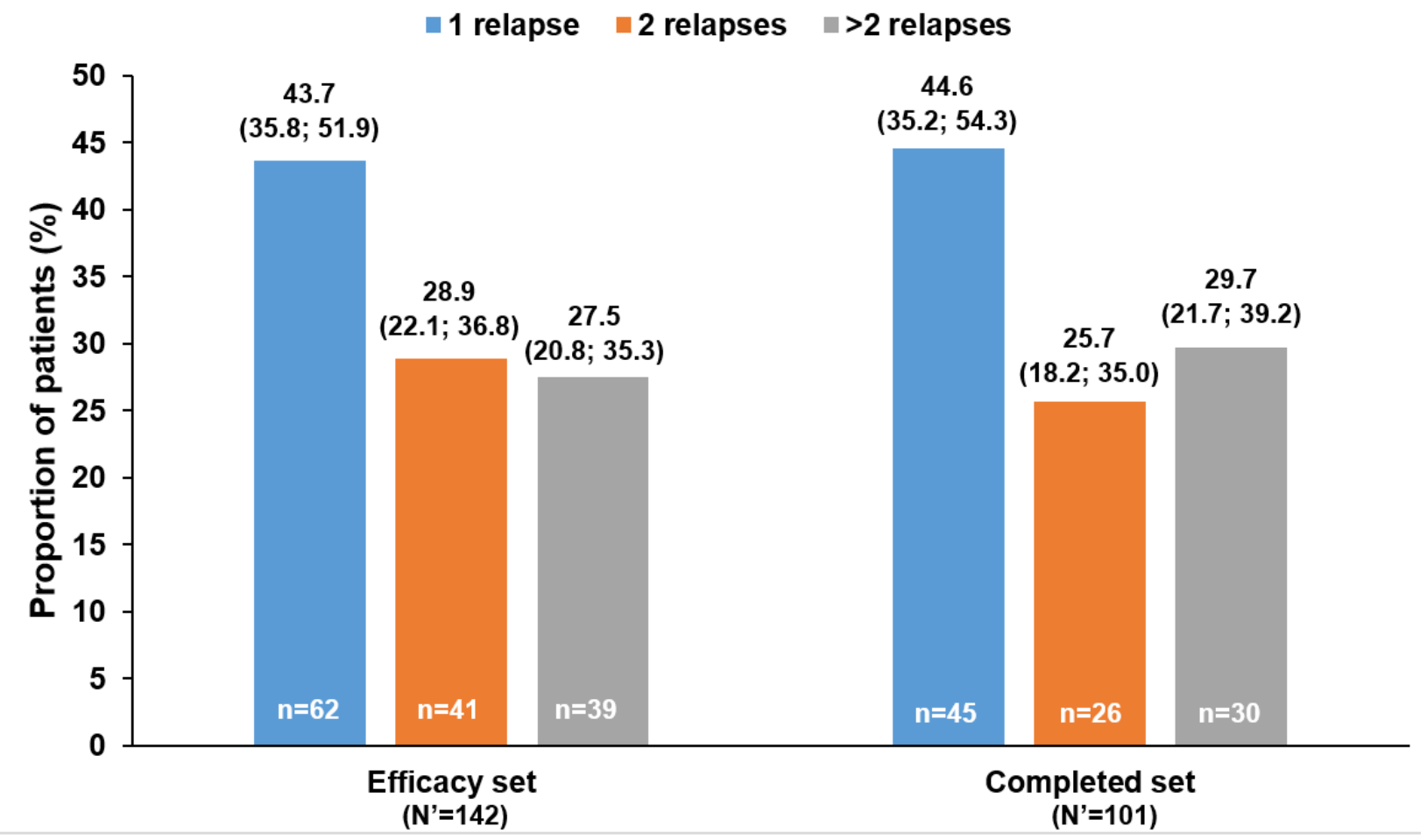

Data presented as percentage of patients (Wald 95\% Cl)

$\mathrm{Cl}$, confidence interval; MS, multiple sclerosis; $\mathrm{N}$ ', total number of patients with relapses; $\mathrm{n}$, number of patients with the individual outcomes 
Figure 3. Time to first MS relapse after the start of fingolimod treatment (efficacy set, by EDSS score at baseline)

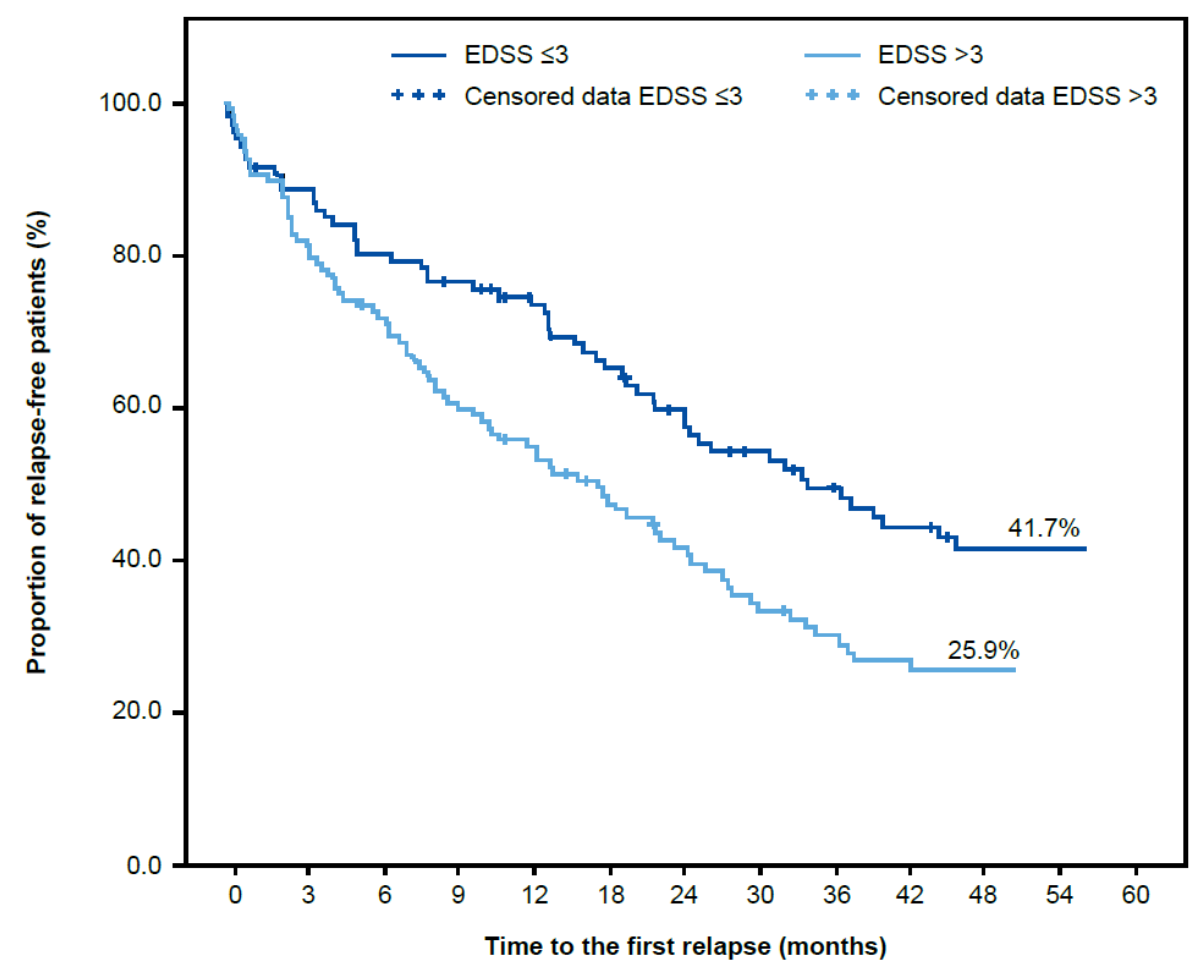

$\begin{array}{lccccccccccccc}\text { At risk EDSS } \leq 3 & 108 & 95 & 86 & 80 & 73 & 61 & 54 & 46 & 41 & 34 & 8 & 1 & 0 \\ \text { At risk EDSS }>3 & 129 & 105 & 90 & 76 & 63 & 51 & 41 & 33 & 28 & 25 & 6 & 0 & \end{array}$

EDSS, Expanded Disability Status Scale; MS, multiple sclerosis 
Figure 4. Severity of MS relapses that occurred in the efficacy set (A) and completed set (B), by visit
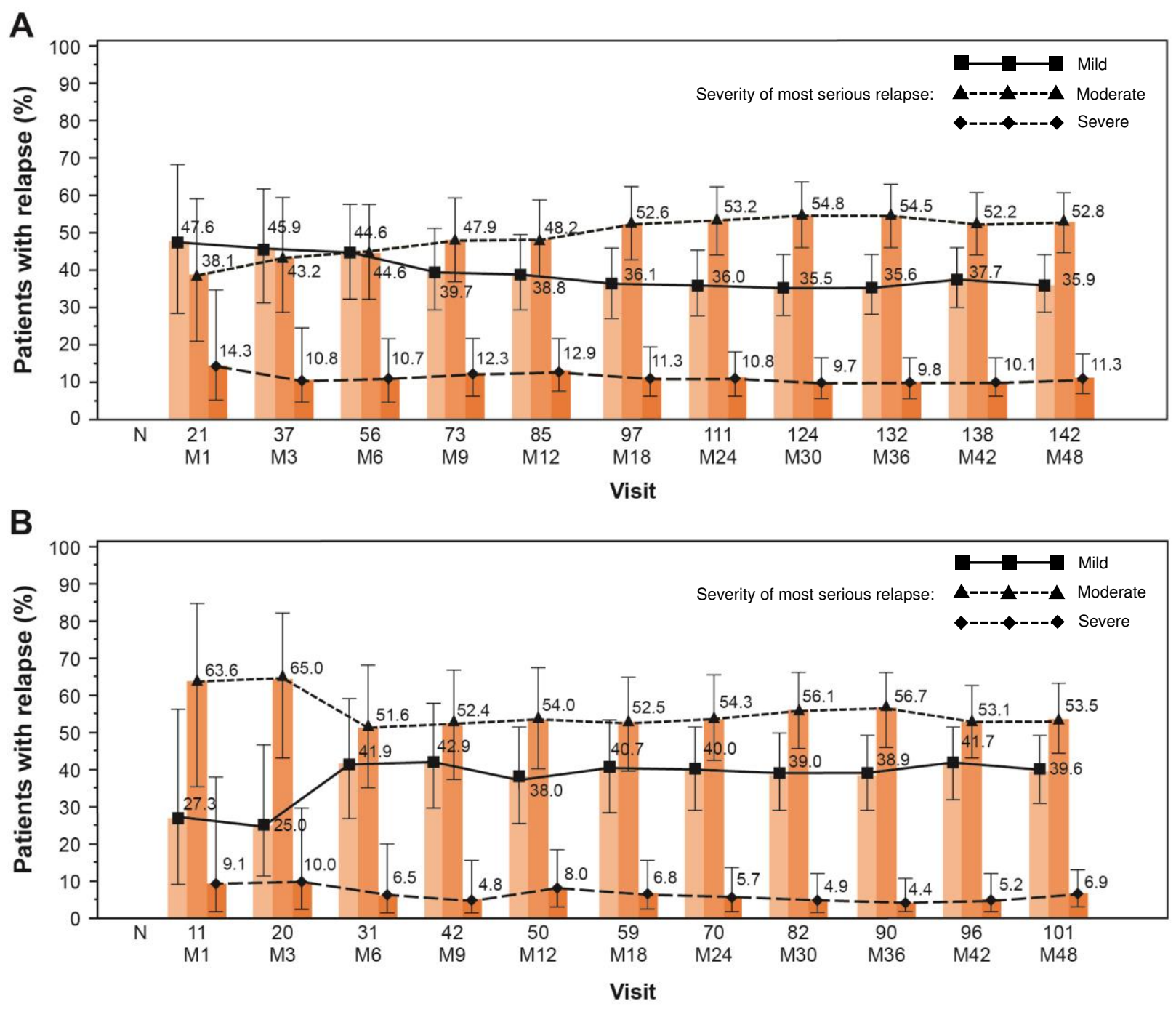

Data presented as percentage of patients (Wilson 95\% Cl)

$\mathrm{Cl}$, confidence interval; M, Month; MS, multiple sclerosis 
Figure 5. EDSS scores in the efficacy set (A) and the completed set (B), by visit

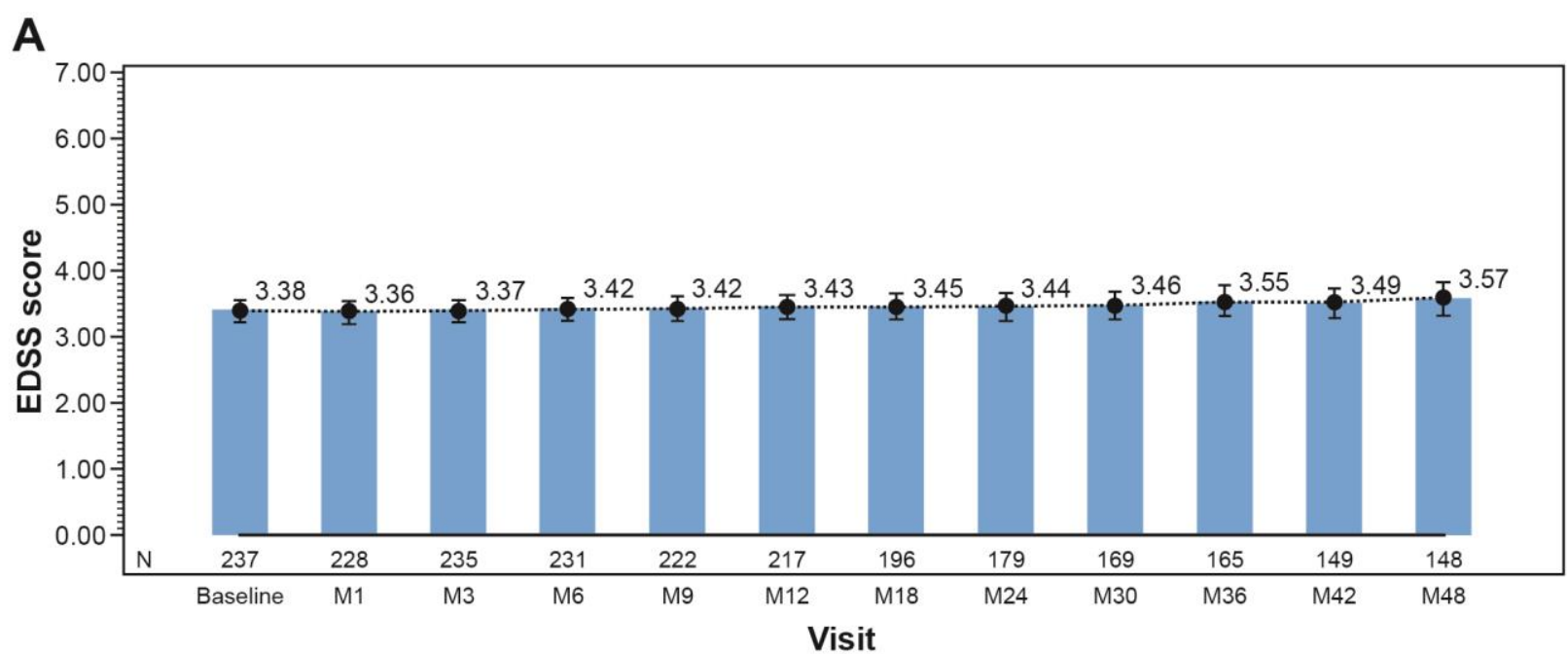

B

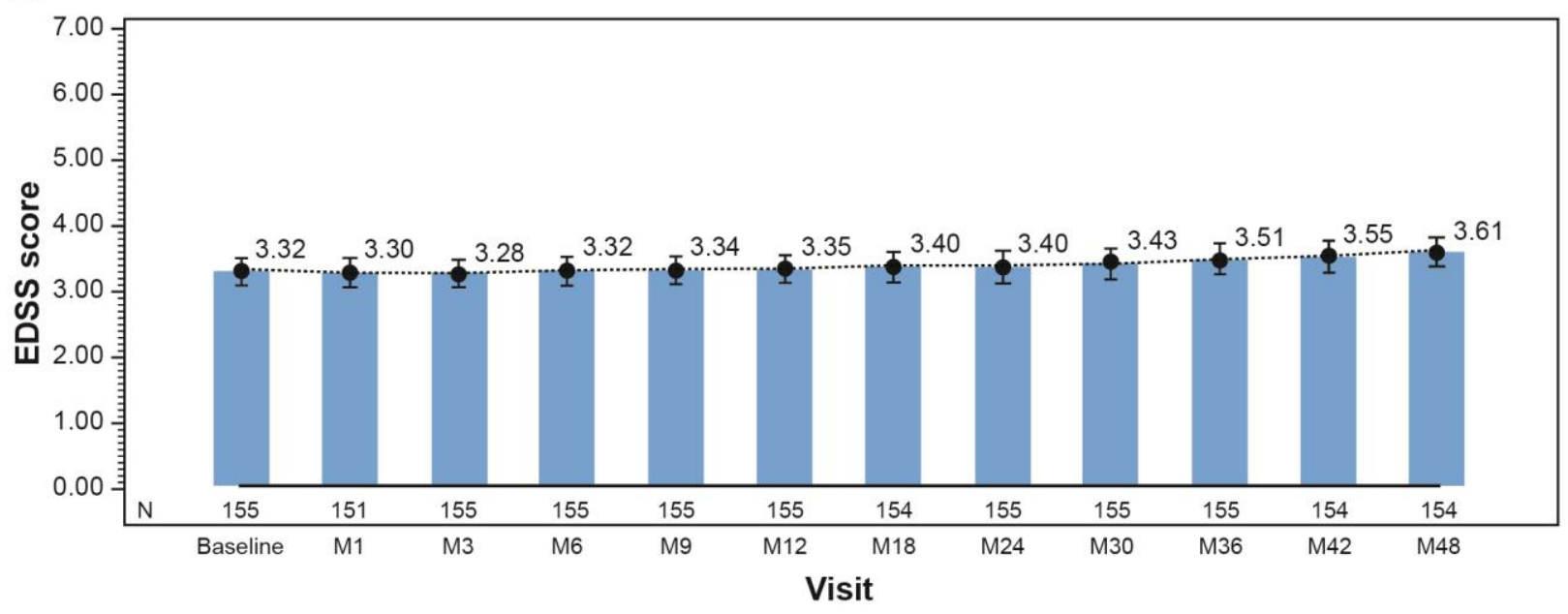

Data presented are Mean $(95 \% \mathrm{Cl})$

$\mathrm{Cl}$, confidence interval; EDSS, Expanded Disability Status Scale; M, Month, N, number of patients 